\title{
Decision-making in paediatric palliative care interpreting
}

\author{
Melissa Contreras-Nourse \\ Children's Hospital and Medical Center, Division of Interpreter Services, United States \\ mcnourse@gmail.com
}

\begin{abstract}
The interpreting profession has long used metaphors or rule statements to describe and teach the ways in which practitioners make decisions (Dean \& Pollard, 2011, 2018). Interpreting students are also often taught that the context of an encounter will dictate their decisionmaking by way of statements such as "it depends". Such pedagogical statements can make talk between a practitioner and a medical professional about the responsibilities of an interpreter during medical encounters difficult. This study is based on the work of Dean and Pollard $(2011,2018)$ on value-based decision-making and is guided by the four principles of biomedical ethics (respect for autonomy, non-maleficence, beneficence and justice). It has sought to provide evidence of the existence, applicability and usability of these frameworks through a single case study of a real-life appointment in which a parent of a palliative care outpatient and a medical professional communicated during a consultation, aided by a medical interpreter.
\end{abstract}

Keywords: values, palliative care, interpreter's decision-making, ethics

\section{Introduction}

One of the weaknesses of context-based decision-making, as suggested by Dean and Pollard (2011), is that it is an "indirect and ineffective" pedagogical method. Therefore, they argue for the use of a teleological approach to decision-making that emphasizes values and optimizes practical outcomes that are more befitting of professional practice (Dean \& Pollard, 2011). In addition, Dean and Pollard (2011) have proposed that interpreters in community settings face four categories of job demand: environmental, interpersonal, paralinguistic and intrapersonal. The environment in which an interpreter practices often has specific goals associated with it and when an interpreter is able to identify these goals, they can maintain neutrality and engage in "ethical interpreting practice" (Dean \& Pollard, 2013).

According to Beauchamp and Childress (2013), medical providers uphold the values of respect for autonomy, non-maleficence, beneficence and justice. These values, often referred to as the "principles of biomedical ethics", are linked to and guide the practices of many professionals in healthcare (Beauchamp \& Childress, 2013). Interpreters also adhere to a series of values, but they are conveyed through a list of rules, of dos and don'ts. In other instances, interpreters are expected to embrace various types of role metaphor as a means of understanding the decisions they make in their practice (Dean \& Pollard, 2018). These 
metaphors include terms such as "conduits", "members of the team", "cultural brokers" or "advocates" (Dean \& Pollard, 2018). The stark differences between the way providers and interpreters talk about their roles and responsibilities can render collaboration between these professionals problematic. According to Dean (2021), it is both necessary and more effective for interpreters to shift towards using the set of values that service-based professionals use (e.g. doctors and nurses) to help them identify multiple effective ethical choices. Dean (2021) has suggested that there is evidence of medical ethics in the decision-making of professional medical interpreters. The motivation for this study was therefore to explore the values medical interpreters demonstrate in their decision-making process while interpreting during an appointment in a palliative care setting.

The study was guided by the following questions: First, how do medical interpreters use their controls to remain in accordance with the various values present during an interpreting assignment? (Controls are what Dean and Pollard (2013) describe as the options an interpreter interacts with and employs to respond to the salient aspects of their work.) Secondly, the researcher wanted to ascertain the answer to this question: How do medical interpreters currently manage the communication patterns that various speakers use in a paediatric palliative care setting? This article attempts to provide evidence of the existence, applicability and usability of Dean and Pollard's values-based decision-making together with the adoption of the four principles of biomedical ethics. Data from a single case study is used to demonstrate how these theories are applied or manifest in practical terms during an interpreting assignment.

\section{Background}

\subsection{Expectations and pedagogy}

The work of medical interpreters is often referred to in the medical literature as following or embodying a "conduit model" (Juckett \& Unger, 2014). This describes the paradigm according to which an interpreter is expected to perform, that is, they are expected to remain "in the background of clinical proceedings" whilst transmitting the content neutrally(Kirby et al., 2016, p. 498). In Araujo-Lane's (2009) medical interpreter textbook this paradigm is noted to be the most recommended role for medical interpreters to work with, one in which "the interpreter listens to the speaker, understands the information and immediately conveys the information as close to the speaker's register as possible" (p. 69). This is the perspective most medical professionals apply to interpreting work. Many medical interpreter codes of ethics, both in the United States and internationally, create constructs of professional ethical behaviour based on the interpreter either adding or subtracting information or not doing so. However, interpreters are also trained to mediate when issues of cultural conflict or misunderstandings arise by explaining matters explicitly to either the provider or the patient; this may entail using clearer wording than was used in the message's original language. The rewording can be used either on its own or in conjunction with the wording originally used. The terms used to describe this professional role vary depending on their source. Examples of these terms include "cultural broker" (Norris et. al, 2005), "cultural mediator" (Kaufert \& Lavallee, 1999) and "cultural coach" (Araujo-Lane, 2009). What is clear - regardless of the terminology used to describe this role - is that medical providers appear to expect the interpreter to intervene only if and when such an occasion arises in a medical encounter, 
although the participants are unlikely to recognise the manifestation of such an intervention. The systematic review of the literature carried out by Brisset et al. (2013) further indicates that current research has focused primarily on describing the role medical interpreters play through varying perspectives of the stakeholders in medical encounters, but also by considering the characteristics of the communication itself during an interpreted consultation. Their work also proposed ways of improving interpreter education (e.g. learning how to work in teams), practice (e.g. adopting ethical principles) and research (e.g. connecting various issues seen in practice that are often studied separately).

In addition, articles written by medical professionals fail to mention that spoken and signed language interpreter education vary greatly. Therefore, it is important to differentiate between the educational backgrounds that different interpreting professionals could have prior to working on an assignment together with a medical professional. Sign language interpreting programmes in the United States range from the associate-level degree to a bachelor level (with a few graduate degree programmes available) to the breadth of education offered to students about interpreting in medical encounters is variable. Walker and Shaw's (2011) study of recent sign language interpreter graduates highlighted the tendency of individuals to accept assignments such as medical appointments despite deficiencies in their medical knowledge (both procedural and terminological) and their practice of "learning by doing", which means that they take great professional risks (Walker \& Shaw, 2011). Furthermore, Walker and Shaw (2011) noted that in any other profession with specialized disciplines "it is unrealistic to expect [interpreters to be fully prepared to work in specialized settings upon graduation from] four-year interpreting programs, much less two-year programs" (p. 105).

These observations are further corroborated by Gonzalez et al. (2018), who state that medical interpreting services are "routinely provided by interpreters without much or any training in this area" (Gonzalez et al., 2018). Many spoken language medical interpreters are often individuals who are themselves members of a linguistic and a cultural minority. In their study, Kaufert and Lavallee (1999) presented two recorded case studies to describe how a medical interpreter practised in a palliative care setting where the culture and family dynamics of the infirm patient were different from those of the medical setting. The interpreters in their study were described as having received training through a short programme (a few weeks) for interpreters or cultural mediators (Kaufert \& Lavallee, 1999). According to Kaufert and Lavallee (1999), the spoken language interpreter often became a clarifier of information for the non-English-speaking patient and their family members by communicating information using culturally appropriate words. In addition, the interpreter also negotiated power dynamics when the patient's extended family was involved in end-of-life decision-making (Kaufert \& Lavallee, 1999). Bolden's (2000) case studies affirm that a medical interpreter's actions are often structured by the goal of the setting, the stakeholders' discourse (medical provider and patient with limited English proficiency) and by the interpreter's "own independent analysis of the ongoing activity and the specific requirement it poses for the participants" (Bolden, 2000, p. 415). An example of an interpreter's analysis of an activity and then implementing strategies to cope with the discourse of an encounter is Napier's (2004) study of Australian Sign Language (Auslan) interpreters. Using a taped university lecture and a with deaf person acting as a receiver, Napier (2004) analysed the recordings of 10 professionally accredited interpreters' renditions of the source text to assess the extent of the 
omissions they produced and their reasoning behind them. Napier's (2004) work revealed that interpreters proactively used omissions as a strategy for managing dense and complex content. However, Napier's (2004) data also indicated that a large number of omissions that occurred in the participants' work were not intentional. Communication management is, of course, not limited to content but rather, as Napier (2004) concludes, to a variety of factors that "could impact upon the rate of and types of omissions, regardless of where the interpreting was taking place, and with whom" (p. 137). An important factor in palliative care interpreting is the interpreter's perception that they do not just work for the patient but potentially for their family too.

Kirby et al. (2016) interviewed 20 professional interpreters working in oncology departments and discovered that a challenge they faced in their clinical encounters was "managing family caregivers". These studies demonstrate that a medical interpreter's work is not solely based on message transfer but also includes the analysis of the demands in the encounter - the stakeholders, the setting and the goals of both.

\subsection{Research on interpreters in palliative care and end-of-life}

Despite an increased interest in the medical community in reaching underserved populations of patients and families, specifically in the field of palliative care (Kirby et. al., 2017; Sharma \& Dy, 2011), current research has focused on the perspective of clinicians, nurses, social workers and public health specialists. Few studies have been dedicated to interpreting studies; however, the following are studies that focused on the medical interpreter's perspective when participating in end-of-life and palliative care encounters.

The work of Kirby et al. (2016) sought to elicit medical interpreters' perspectives on what causes strain in their work during oncology and palliative care encounters. Some of the challenges that interpreters cited in this work included:

- communicating the meaning of the term "palliative care";

- working within the boundaries of their code of ethics; and

- the "emotional burdens faced within and outside of consultations in palliative care concepts" (Kirby et al., 2016, p. 499).

Their work called for more support and resources to be afforded interpreter training programmes. The qualitative work of Schenker et al. (2012), which used both a national survey of professional medical interpreters and 43 participants in their focus groups, led to a similar finding. They revealed that medical interpreters desire training not only for themselves but also for the medical providers in the realm of cultural differences when discussing end-of-life concepts. This training was needed in order to improve such interpreting challenges as vague language and the use of metaphors and medical terms that did not have target language equivalents. Through the focus group work of Norris et al. (2005) with multiple groups of spoken language interpreters, the researchers were able to identify various factors that affect interpreters when delivering services in end-of-life clinical encounters in addition to dealing with the communication dynamics involving family caregivers.

According to Norris et al. (2005), interpreters also expressed and acknowledged issues with their multiple roles as they relate to maintaining professional ethical boundaries, respecting 
the cultural or religious practices of the patient or family caregiver, and professional expectations. Schenker et al. (2012) also revealed the importance of the professional interpreter's place and that they should know their role during an end-of-life encounter. Their work demonstrated that medical interpreters tend to feel more comfortable and report that end-of-life discussions proceed better when both they and the provider are clear about the interpreter's role in the encounter.

In summary, the studies that took the interpreter's perspective to understand the issues that can occur in linguistic and culturally distinct palliative care settings noted the lack of specialized training for and in healthcare settings. These studies also described the constraints of the conduit model and codes of ethics tailored to using this model, which have been construed as shortcuts commonly referred to as "roles" by both the profession of interpreting and that of medical providers.

\subsection{Values}

Professional associations for both spoken and signed language interpreters have created codes of ethics to help practising professionals think critically about their work practices, in essence, their professional values. These codes of ethics have evolved as the profession's paradigms have shifted and formal educational opportunities have become standardized. When one examines the code of ethics of either the Registry of Interpreters for the Deaf (RID) ${ }^{i}$ or the International Medical Interpreters Association (IMIA)," each of these organization's tenets can be linked back to any of the four principles of biomedical ethics. As previously discussed, the four principles of biomedical ethics include respect for autonomy (the foundation for informed consent), non-maleficence (this requires that no acts set back an individual - in essence not inflicting harm), beneficence (the duty to protect and prevent harm befalling another), and justice (equal distribution of resources along with their risks and costs) (Beauchamp \& Childress, 2013). Yet, based on the research data described above, it appears that medical interpreters still feel challenged to make certain professional decisions for fear of deviating from the "role" that the conduit model imposes. In addition, as Dysart-Gale (2005) points out, the conduit model of communication does not itself present "guidelines that permit interpreters to structure their interventions" (p. 97); it is not an ethical construct in and of itself.

According to Dean (2014), short cuts to describing ethical behaviours in the interpreting profession commonly include the following: the interpreter concerns themself only with message transfer and anything outside of that is not the job of the interpreter. In line with this, they may take action only if something is directly affecting their ability to execute the interpreting work. If professional values are preventing an interpreter from making ethical choices, then it seems logical that interpreters must be educated about ethics. However, a point of contention among educators of interpreters is precisely how to teach professional ethics. According to Baker and Maier (2011), interpreter education about ethics should be constructed in a way that students recognize that "ethical decision making is a feature of all situations" (p. 4) and it should allow for critical reflection about behaviours without using a deontological approach (i.e. about rights and wrongs). Furthermore, Dean (2014) states that ethical thinking and the task of facilitating communication should not be seen as separate practices or situations: rather, practitioners put ethics into practice moment by moment as 
they communicate with their clients. She concludes that decision-making and "taking moral action is a complex psychological phenomenon that draws on the decision-makers' cognitive and affective processes" (Dean, 2014, p.72 ).

Clearly, a medical interpreter's work does not occur in a vacuum. Often, the communication setting in which an interpreter practises has specific values, but most professionals are not taught these, nor are they usually aware of the utility of these values as it pertains to their decision-making (Dean, 2021). The interpreting profession should, Dean (2021) avers, "attempt to take its existing ethical ideals and compare them to those of the four core principles prevalent in healthcare" (p. 212).

A paediatric palliative care consultation has its own values that an interpreter must identify in order to practise ethically. According to the American Academy of Pediatrics guidelines on hospice and palliative medicine and its committee on hospital care (2013), a paediatric palliative care team should aim to provide treatments that relieve suffering. Relief can manifest itself in the patient and their family physically (e.g., pain or dyspnoea), psychologically (e.g., depression), socially (e.g., isolation), in a practical respect (e.g., financial stress) and/or existentially or spiritually. In addition to providing support and resources to relieve suffering, the palliative care team works to facilitate informed decision-making (an aspect of the principle of respect for autonomy) by patients, families and healthcare professionals (section on Hospice and Palliative Medicine and Committee on Hospital Care, 2013). According to the American Academy of Pediatrics committee on bioethics (2016), informed consent, permission, assent and refusal are not "discrete events" but are rather a process that requires "physician-patient-family communication and education" (p. 3, 5). The longitudinal nature of a paediatric palliative care team's involvement with a family and the minor patient further highlights the reality that discrete events of communication do not occur but rather that the team can reassess interventions in the plan of care as the patient's status changes over time (Santoro \& Bennett, 2018).

A medical interpreter not only manages the task of language interpreting (transferring information from one language into another); they also assess several variables that interact with the message transfer. This includes the values of their own profession to make decisions, the values of the environment in which they work and the communication objectives (thought worlds) of the parties involved in the encounter itself.

From a single case study, naturally occurring data were collected from an authentic paediatric palliative care outpatient appointment in order to describe the nature of an interpreter's decision-making process in relation to the values of the setting. With this data, the researcher is able to provide evidence of the way in which value-based decision-making and the four principles of biomedical ethics manifest themselves during an interpreting assignment.

\section{Research method}

\subsection{Study design}

This study used a qualitative methodology. The researcher, also a medical interpreter, selected her place of employment as the setting for this study. According to Thomas (2011), 
the setting is one of local knowledge to the researcher (her place of employment), an environment she is familiar with; therefore, her knowledge allows her the opportunity to identify and discuss the context of the study in a more detailed manner (Thomas, 2011). In this case, an outpatient palliative care consultation appointment was selected as it logistically offered more time for the limited English proficient (LEP) parent or guardian to ask questions about the research consent forms without the additional pressure of a child's health status (cardiac arrest, coma, etc.) weighing on their mind. The outpatient setting also offered a more conducive environment for using a recording device to keep a record of the palliative care consultation for further analysis. An inpatient setting (ICU, surgical unit, etc.) would place physical constraints (high foot traffic, bulky medical equipment, acoustics, etc.) on the ability to use such devices.

To safeguard against researcher bias, in particular due to the researcher's observing an interpreter colleague and medical staff she typically works with, the following triangulation approaches were used: observation of the visit with field notes being compiled by the researcher; transcripts of the encounter in conjunction with interviews with the providers from the palliative care team and the medical interpreter (Creswell, 2014). In the data analysis, the researcher used the critical incident technique to examine the observable and objective interpreter behaviours that occurred in this setting.

With the institution's ethics approval having been obtained, the recruitment of potential candidates began with the help of a palliative care team member. To be eligible to participate in the study, the minor patient's parent or guardian had to require the use of interpreting services for their appointment. The medical interpreter's eligibility hinged on their status as either a contractor or a staff interpreter for the hospital. Those palliative care team members present at the time of the appointment participated in the study. All the participants were provided with both verbal accounts of the consent form and printed copies in either English or Spanish (the patient's and their parent's first language). These included information about their rights as voluntary participants in this research study, the purpose of the research, the time they were required to commit to the study if they agreed to participate, along with the risks/benefits they faced as participants. The researcher met with each of the participants prior to the start of the appointment to respond to any questions or concerns about the consent form.

A total of five voluntary participants were enrolled for this study. The palliative care team comprised three providers as participants: a medical provider, a medical social worker and a nurse case manager. A staff medical interpreter also participated in the study. Parental consent was sought and obtained; the patient was too young to indicate their assent.

\subsection{Data collection}

An outpatient palliative care appointment between a patient, the patient's parent, the palliative care team (medical provider, medical social worker and nurse case manager) and the medical interpreter was observed. This particular encounter lasted 66 minutes. With parental consent, an audio recording of the appointment was made. The researcher observed and recorded the appointment in its entirety. A recording device with the app VoiceRecorder was used to capture the dialogue. 
Transcription was executed by the researcher using the guidelines suggested by Hale and Napier (2013). The researcher also kept field notes of this appointment to refer back to specific instances (using the recorder's time stamp) of physical activity which may have had an impact on an interpreter's decision-making capacity (such as the patient's cries hindering auditory access to the message) which were not captured by the audio recording. A drawing of the seating arrangement was made in the event that it became relevant to the interpreter's decision-making.

Some time after the appointment, the researcher interviewed the medical interpreter and the palliative care team members during separate appointments to explore points of interest that arose during the initial patient encounter. The parent of the patient was not invited back for further interviews as the main research question was couched in biomedical ethics used in the paediatric palliative care setting. The biomedical ethics were used to frame the decisionmaking by the professionals involved in the setting: the medical providers and (hypothetically) the medical interpreter. These retrospective semi-structured interviews were not recorded; however, the researcher made and kept notes from the interviews. According to Bachiochi and Weiner's (2002) recommendations, the researcher recorded the conversations as verbatim as possible during the sessions; these consisted of both complete and incomplete sentences. Post-hoc summaries were then written from these notes while the researcher's memory of the event was still fresh.

\subsection{Analysis}

After completing the appointment transcript, the document was analysed using the critical incident technique as this technique enables a researcher to explore the turning points of an activity and what is being accomplished while the activity is being executed (Butterfield et al., 2005). The time points selected appear to indicate junctures in the interpreter's decisionmaking when she used controls in response to the demands of the appointment. These were therefore selected because they were observable and objective behaviours that any other interpreting professional could recognize as possible controls. Dean and Pollard (2013) describe controls as an interpreter's behaviour that is both observable and overt, indicating the way they respond to an aspect of their work via their skills, knowledge and experience pertaining to the assignment. The common professional practice of using simultaneous and consecutive interpreting modes became significant to the researcher because the context in which the medical interpreter decided to toggle between both modes during the encounter, and how often this occurred, was unclear. Although the researcher observed this switch occur throughout most of the encounter, she explored what compelled the interpreter in her decision to switch between the two modes by focusing on two specific time stamps. The use of additions, although common in the interpreting field, strays from what medical providers view as the interpreter's work, that is, message transfer and cultural mediation. A time stamp was selected from the transcript to explore why the interpreter felt compelled to use an addition during the ensuing dialogue, as it appeared at face value unrelated to either cultural mediation or a message transfer error, both of which the medical providers could perceive as part of her work. The researcher also chose to focus on two specific time stamps in which some dialogue was interpreted but other parts were not. All five-time stamps are described fully in Table 1. 
The data represented in Table 1 guided the final draft of the questions used for the separate semi-structured interviews with the medical interpreter and the palliative care team members. The interviews took place in a coffee shop located in the hospital; they lasted between 30 and 45 minutes. The content of the interview questions for both the medical interpreter and the palliative care team focused on their expertise in their own respective fields (e.g. decision-making while working as an interpreter in a paediatric medical encounter and, for the palliative care team, those values that are core to their work in paediatric meetings with parent(s) in need of their services regardless of the involvement of an LEP individual). The interview questions for the medical interpreter focused on specific examples introduced from the transcript of the encounter and questions about the interpreter's understanding of the palliative care appointment.

In addition, the researcher prefaced the medical interpreter's interview with a preamble to create a dialogue that was not interrogatory but rather exploratory. The interview questions used for the palliative care team members focused on the values they pursue in and their expectations of the setting. The researcher's notes were used to create post-hoc summaries of the interviewees' responses. In the analysis of these summaries keywords and themes emerged that both the medical interpreter and the palliative care team used to talk about the work that is carried out during such a palliative care appointment (see Table 2). The data presented in Table 1 and Table 2 were used to help triangulate the data.

\subsection{Limitations}

Given that the researcher employed a qualitative design, it is by its nature sensitive to her bias, interpretations and claims shaped by her previous experiences (Creswell, 2014). In the interests of transparency, she made subjective decisions both in taking note of what was said by the medical interpreter during her interview and in applying the theoretical frameworks (value-based decision-making and the four principles of biomedical ethics) to create the ensuing arguments. Triangulation strategies were implemented in the study design to decrease bias as much as possible.

By design, data from a retrospective interview will demonstrate a difference between the time and place the actual events an interviewee is being asked about and the time of the interview itself (Diefenbach, 2008). Furthermore, according to Diefenbach (2008), the interview data obtained during such interviews "cannot reveal or demonstrate with certainty whether the statements provide a true picture" of what was happening at the time of the actual event in question. The nature of the data obtained from these interviews is sensitive to the way individuals wish to have themselves perceived for reasons such as, but not limited to, these: the participants knowing the interviewer by being in the same workplace or by working at different organizational levels in an entity (Al-Yateem, 2012). Furthermore, according to Bachiochi and Weiner (2002), the use of recording devices "can make some participants uncomfortable or self-conscious" (p. 167), therefore affecting their participation and the extent of their candour with the interviewer. For these reasons, the researcher chose to not record the semi-structured retrospective interviews in the hope of fostering frank participation and reducing the effect of distortion as a result of the time gap between the palliative care encounter and the interview or any distortion resulting from the participants' wish to present a different reality. 
Contreras-Nourse, M. (2021). Decision-making in paediatric palliative care interpreting. Linguistica Antverpiensia, New Series: Themes in Translation Studies, 20, 209-226.

\section{Findings}

From the 66-minute recording the researcher selected five examples in which to look for specific evidence, using the critical incidence technique to support or deny the theoretical frameworks previously presented. These five decision-making junctures are what appear to be controls used by the Spanish medical interpreter, Silvia, iii during the appointment.

Table 1: Decision-making junctures

\begin{tabular}{|c|c|c|c|}
\hline Time stamp & $\begin{array}{l}\text { Antecedent } \\
\text { information }\end{array}$ & Dialogue context & Outcome \\
\hline $\begin{array}{c}\text { (1) } 13: 52.42- \\
14: 27.27\end{array}$ & $\begin{array}{l}\text { The parent asks the } \\
\text { physician if it would } \\
\text { be best to postpone } \\
\text { the surgery until } \\
\text { after they return } \\
\text { from abroad or if it } \\
\text { would be okay to } \\
\text { travel a few months } \\
\text { after surgery took } \\
\text { place. }\end{array}$ & $\begin{array}{l}\text { The interpreter } \\
\text { describes first to } \\
\text { the parent and then } \\
\text { the physician } \\
\text { the neurosurgeon's } \\
\text { suggestion about } \\
\text { how to prepare } \\
\text { to travel abroad } \\
\text { after surgery. } \\
\text { Parent then asks if } \\
\text { any wound care } \\
\text { would still be } \\
\text { needed while they } \\
\text { are abroad. }\end{array}$ & $\begin{array}{l}\text { - Interpreter adds } \\
\text { information from another } \\
\text { appointment. (Addition) } \\
\text { - Parent continues to seek } \\
\text { clarification on the healing } \\
\text { process after surgery. }\end{array}$ \\
\hline $\begin{array}{l}\text { (2) } 16: 49.74- \\
17: 00\end{array}$ & $\begin{array}{l}\text { The physician } \\
\text { describes an } \\
\text { average healing } \\
\text { timeline for the } \\
\text { baclofen pump } \\
\text { placement, then the } \\
\text { parent asks how } \\
\text { long it would take } \\
\text { the patient to heal } \\
\text { from hip surgery. }\end{array}$ & $\begin{array}{l}\text { The bilingual Nurse } \\
\text { Case Manager } \\
\text { (NCM) tells the } \\
\text { parent that healing } \\
\text { times vary between } \\
\text { individuals. }\end{array}$ & $\begin{array}{l}\text { - Interpreter does not } \\
\text { interpret the Spanish side } \\
\text { conversation between NCM } \\
\text { and parent. } \\
\text { - Doctor's estimated time } \\
\text { for healing not interpreted } \\
\text { into English for the } \\
\text { parent. (Omission) } \\
\text { - NCM interprets her own } \\
\text { statement into English for the } \\
\text { team. }\end{array}$ \\
\hline $\begin{array}{l}\text { (3) } 17: 00- \\
17: 51.52\end{array}$ & $\begin{array}{l}\text { NCM and the } \\
\text { patient's parent } \\
\text { engage in a side } \\
\text { discussion. }\end{array}$ & $\begin{array}{l}\text { Parent explains that } \\
\text { the child has healed } \\
\text { fast in the past from } \\
\text { simple surgery. The } \\
\text { NCM asks how the } \\
\text { other parent feels } \\
\text { about the } \\
\text { upcoming } \\
\text { surgery. }\end{array}$ & $\begin{array}{l}\text { - NCM interprets her own } \\
\text { question from the side } \\
\text { conversation into English for } \\
\text { the team. } \\
\text { - Interpreter interprets most } \\
\text { of the conversation but not all } \\
\text { of the utterances. } \\
\text { (Omission) }\end{array}$ \\
\hline $\begin{array}{l}\text { (4) } 26: 05.84- \\
26: 36.46\end{array}$ & $\begin{array}{l}\text { The parent describes } \\
\text { her child's previous } \\
\text { post-operative fever } \\
\text { and seizures. }\end{array}$ & $\begin{array}{l}\text { The parent } \\
\text { explains that she } \\
\text { is a little fearful of } \\
\text { the upcoming }\end{array}$ & $\begin{array}{l}\text { - Interpreter switches to } \\
\text { simultaneous mode once the } \\
\text { parent starts to describe her }\end{array}$ \\
\hline
\end{tabular}




\begin{tabular}{|c|l|l|l|}
\hline Time stamp & $\begin{array}{l}\text { Antecedent } \\
\text { information }\end{array}$ & Dialogue context & Outcome \\
\hline & & $\begin{array}{l}\text { surgery in case the } \\
\text { patient develops a } \\
\text { fever but is very } \\
\text { scared of seizure } \\
\text { activity. }\end{array}$ & $\begin{array}{l}\text { fears. (Consecutive vs } \\
\text { simultaneous) } \\
\text { - Overlapping talk } \\
- \text { Interpreter switches back to } \\
\text { consecutive mode once the } \\
\text { provider begins to speak to } \\
\text { the parent. }\end{array}$ \\
\hline (5) 28:15.87- & $\begin{array}{l}\text { The physician talks } \\
\text { about the goal of } \\
\text { post-operative } \\
\text { pain management. }\end{array}$ & $\begin{array}{l}\text { The parent asks } \\
\text { how long a hospital } \\
\text { stay they will have } \\
\text { after these } \\
\text { procedures and } \\
\text { enquires about pain } \\
\text { management. }\end{array}$ & $\begin{array}{l}\text { - Overlapping talk } \\
\text { - Interpreter switches to } \\
\text { simultaneous mode once } \\
\text { the parent starts to pose } \\
\text { their question. } \\
\text { (Consecutive vs simultaneous) } \\
- \text { Interpreter deviates from } \\
\text { source text. } \\
- \text { NCM responds to one of } \\
\text { the questions in Spanish but } \\
\text { neither the parents } \\
\text { questions nor the NCM } \\
\text { response was produced in } \\
\text { English by the interpreter. }\end{array}$ \\
& & $\begin{array}{l}\text { - NCM states in English } \\
\text { parent's question after } \\
\text { exchange. }\end{array}$ \\
\hline
\end{tabular}

Furthermore, these examples suggest that using the lens of values-based decision-making instead of relying solely on sociolinguistic constructs and metaphors can benefit the way interpreters describe, analyse and share the way they work with those in their own field as well as with other professionals.

What follows is a discussion that focuses on the conduct of the professionals who participated in the palliative care appointment and not on the parent. The reason for this choice is twofold: most laymen lack knowledge of biomedical ethics and are unaware that medical interpreters have to follow a professional code of ethics. The themes and keywords of the retrospective interviews can be found in Table 2.

Table 2: Retrospective interviews themes and keywords

\begin{tabular}{|l|l|l|}
\hline Medical interpreter & Palliative care team & Principle of biomedical ethics \\
\hline clarify & $\begin{array}{l}\text { clarification } \\
\text { second opinions }\end{array}$ & $\begin{array}{l}\text { respect for autonomy } \\
\text { (informed consent) }\end{array}$ \\
\hline $\begin{array}{l}\text { inclusion of parent work } \\
\text { together to help }\end{array}$ & $\begin{array}{l}\text { work together } \\
\text { interdisciplinary }\end{array}$ & $\begin{array}{l}\text { non-maleficence } \\
\text { (do no harm) }\end{array}$ \\
\hline informative & provide information & beneficence \\
\hline
\end{tabular}


soothing

feel more at ease place gives comfort

what do they think, feel?

\section{Discussion}

The addition made by the medical interpreter, Silvia, at time stamp 1 was of particular interest, given the interpreting profession's view of such an action: an error in the linguistic work an interpreter should execute and as an ethical violation. Yet Napier (2004) explains in her work that both omissions and additions are interpreting strategies that are used to manage the content of the source text in an efficient manner. From an ethical perspective, Silvia's addition can be described as an extension of the biomedical principle of respect for autonomy, called "positive obligation". According to Beauchamp and Childress (2013), positive obligation is the fostering of autonomous decision-making by way of both action and the respectful treatment of information disclosure. Therefore, we can see that Silvia's action is in fact in line with the values inherent in both the context of palliative care and in medicine in general, and also those of her own profession.

At this juncture we pause to take a closer look at this point so as to enhance our understanding of the ethics involved. The parent was asking if the patient would be sufficiently healed to travel after having had surgery or if it would be best to postpone surgery until they returned from their trip. After interpreting the question, Silvia then explains to the physician that she had interpreted for the parent at the surgical appointment where this particular procedure was discussed. The following excerpt from the transcript illustrates what transpired afterwards.

(13:57.47) Interpreter: Se acuerda que le dijo la doctora que era mejor de hecho, lo único tenían de acuerdo es de tener todo los suministros que usted necesite. [Y tener la medicina.

Back translation: Do you remember that the doctor told you it would be better in fact, the only thing that was agreed to was to have all the supplies that you would need. [And have the medicine

(14:07.46) Parent: [No necesita curaciones?

Back translation: Isn't there any cares for the wounds?

(14:09.78) Interpreter: Won't he need ... Sorry I was telling her that remember neurosurgeon said um you will, it's better they do it before. But she will also have to have backup in oral, just in case you know the pump doesn't work or anything. But she would prepare to have it done before.

(14:26.19) Doctor: Yeah

(14:27.27) Interpreter: Won't it need any um, any tape, any dressing for the wound or anything?

As can be seen, Silvia's addition was conveyed to both the parent and the palliative care team, so that all the participants were aware of what was being said. This event illustrates the reality of interpreter agency that many interpreting professionals engage in but are often hesitant to share with colleagues or other professionals they work with as it may be viewed as stepping out of their primary role of acting as a conduit (message transfer). Other interpreters may have used the term "advocate" to describe the behaviour (action) of using an addition. However, advocate, in the words of Dean (2021), would be a "poor word choice" (p. 200) as Silvia is not claiming that the provider has done something wrong against the parent and the 
patient. According to Dean (2021), what often compels interpreters to"...speak up on that patient's behalf is when they witness a value inadvertently compromised by the provider, a value the provider already holds" (p. 200).

In this case, Silvia added information that she believed advanced the parent's primary objective of learning about the impact upcoming surgery would have on the patient. The value Silvia upheld aligns with a value the palliative care provider already holds: to facilitate informed decision-making (an aspect of the principle of respect for autonomy) (section on Hospice and Palliative Medicine and Committee on Hospital Care, 2013).

When the researcher asked the palliative care team during their retrospective interview about this addition, the physician stated that they do not expect an interpreter to add unsolicited information. The physician elaborated that this action can be a double-edged sword, therefore an interpreter should use additions judiciously. This statement aligns with 'do no harm', an extension of the principle of non-maleficence, which in this case means one should not practise outside one's area of expertise.

This time stamp exemplifies the notion that interpreter decision-making when using ethical constructs can be assessed in terms of which professional values are either prioritized or forfeited. Until now, this has only been described as happening theoretically by Dean and Pollard's work. By using the frameworks of biomedical ethics and demand control schema, this addition can now be articulated not only for reflective practice purposes but also as a way of talking to other healthcare professionals about why a certain approach was taken without using language such as "I was being an advocate".

At time stamp 2 the researcher noticed that the side conversation the nurse case manager (NCM) and the parent were having in Spanish was not interpreted for the rest of the Englishspeaking team. Yet at time stamp 3 there were parts of the discourse that were interpreted into English (when the source text was in Spanish), but other parts were not. During the postconsultation interview, when discussing these time stamps, the researcher asked Silvia what had impelled her to decide which utterances to interpret and which not when the NCM (a native Spanish speaker) and the parent engaged in a side conversation. Silvia stated that she perceived the appointment as an informal informative meeting with the objective of making the parent feel comfortable with the current plan for their child's care. Silvia believed that the NCM was simply seeking clarification from the parent; therefore, she chose not to interpret their conversation. Furthermore, Silvia stated that she perceived the parent's primary objective of the meeting to be to learn about the pain that can result from two different planned surgical procedures: surgical placement of a baclofen pump and an orthopaedic procedure.

According to Dean and Pollard (2013), interpersonal demands are specific features tied to the interaction of the participants and the interpreter. These include, but are not limited to, power or authority dynamics, emotional tone or mood and speakers' communication objectives (thought worlds), a combination of "mental influences upon that person's perceptions, cognitions, feelings and behaviors at a specific moment in time" (Dean \& Pollard, 2013). For the researcher applying demand control schema, Silvia's control of not interpreting the side conversation can be interpreted as being in accordance with her profession's value of non- 
interference. This control of managing the communication, through the lens of the four core principles, is in fact an extension of respect for autonomy. In other words, the interpreter saw that the palliative care team member was engaged in a conversation that was increasing the parent's capacity to make fully informed autonomous choices in support of the patient's wellbeing - informed consent being a part of respect for (patient) autonomy. Therefore, the inaction of not interpreting is supportive of the creation of a space in which the parent and the palliative care team can meet their respective goals. Here we can see that by evaluating the values of both the setting and the interpreting profession, we can describe the practitioner's decisions without needing to explain why she had to "break from a role".

Silvia appeared to toggle back and forth between simultaneous and consecutive interpreting throughout most of the encounter. Time stamps 4 and 5 were selected for exploration as several critical incidents were noted here: overlapping talk between three participants (the $\mathrm{NCM}$, the parent and the physician), the interpreter toggling between simultaneous and consecutive mode and deviating from the source text. At this time stamp the parent was enquiring about her child's possible hospital stay postoperatively (see Table 1). To understand and fully review the matters that Silvia used in her decision-making, the researcher created a demand constellation (see Figure 1), using her remarks during the retrospective interview.

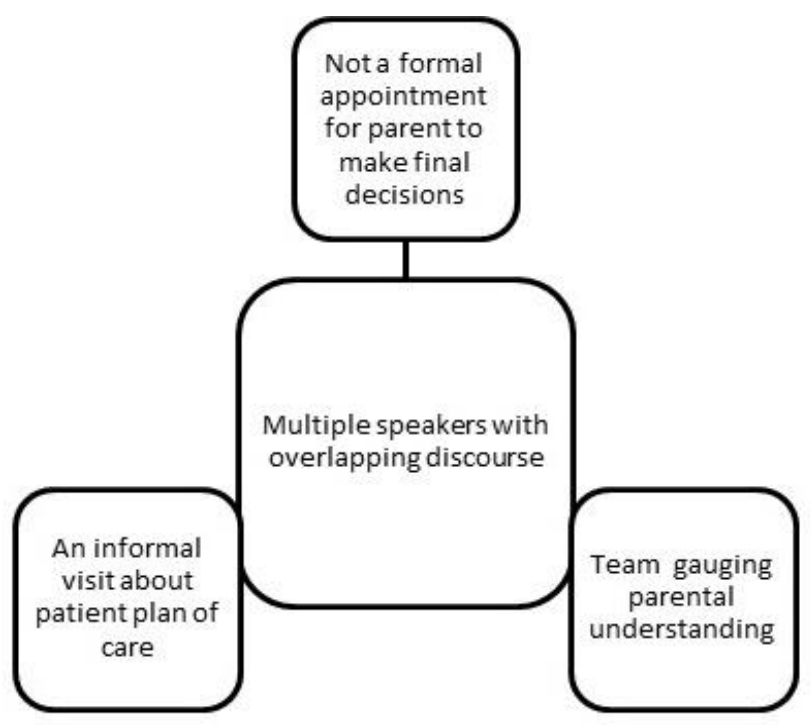

Figure 1: Demand constellation

Dean and Pollard (2013) state that an interpreter can better narrow their choices for controls in their work the more they know about the situation and the people involved, in this way "optimally mitigating negative consequences" (p. 113). In analysing time stamp 5 and using the demand constellation, we can see that by using a simultaneous mode the palliative care team was given the opportunity to gauge the parent's understanding of the child's plan for surgery. It also allowed the team to respond to concerns in an informal environment where medical decisions do not need to be made immediately. This is a manifestation of the value of informed consent (principle of autonomy) which Beauchamp and Childress (2013) refer to as an individual's actual choices or known preferences, not presumptions. In the field of medicine, Beauchamp and Childress (2013) state that it is a health professional's obligation to accommodate their patient's wishes to receive information and make decisions, because any 
assumptions made by the professional about a patient, given that individual's particular association to a community or cultural values or world view, would constitute a failure to respect the patient's autonomy. This value was further substantiated by the comments of the palliative care team members during their interview. The physician explained that from a medical perspective the team do very little intervention themselves; instead, they are there to provide clarification on decision points and can also offer a second opinion (for the family).

Respect for patient autonomy is a professional value that the interpreting field also shares. Silvia upheld this value by not interfering in the communication process either by asking for turn taking or by using another type of control. Yet, by her making this choice, the palliative care team and the parent were prevented from gaining access to all the uttered statements in their preferred language. In addition, a resulting demand of Silvia's control both by not interpreting all of the conversation (omissions) and by toggling between interpreting modes (consecutive to simultaneous) was her deviation from the source text during this discourse. When this deviation occurred, the NCM, who is bilingual, reacted to it and what transpired can be seen in the transcription excerpt below:

(28:34.19-28:36.55) Doctor: [But I think it'll probably be three to four days in the hospital

(28:36.85-28:39.15) Interpreter: Pero probablemente dos a tres días en el hospital.

Back translation Interpreter: But probably two or three days in the hospital

(28:39.58) Nurse Case Manager: Tres a cuatro

Back translation Nurse Case Manager: Three to four.

(28:40.67-28:42.68) Interpreter: Dos o (.) ] Tres a cuatro. Three to four days!

As illustrated above, the NCM manager interpreted the physician's message (the original source text) after the deviated interpretation was rendered. A second later, Silvia repeated the source text in both Spanish and then in English. In this situation, the objective of responding to the parent's concern about the care plan and providing immediate access to information using simultaneous mode could not be pursued at the same time: instead, one value had to be deprioritized. According to Dean and Pollard (2013), a positive consequence is described as the intended effect the interpreter was expecting their decision to create in the setting, whereas a negative consequence is "what is forfeited as a result of that decision" (p. 110). Therefore, this situation demonstrates innumerable values. It also depicts the professional value of accuracy, which was upheld by Silvia's decision to render the source text provided by the NCM. The interpreter's value of accuracy not only supports the value of the palliative care team's effort to ensure informed consent, but it also demonstrates Silvia's desire to uphold the value of non-maleficence. In this case, non-maleficence manifests itself by preventing further harm that could occur from delivering only the deviated source text. Through the lens of biomedical ethics and the demand control schema we can evaluate a practitioner's work with flexibility and tangibility, as Dean has proposed in many of her works. Regarding the author's research questions about how an interpreter uses their controls to remain in accordance with the values in the paediatric palliative care assignment, it was observed that Sylvia used additions, not interpreting information, and the toggling of interpreting modes to ensure that both parent and medical team had their objectives met during the appointment. Sylvia also ensured that she remained in accordance with the value interpreting accuracy when a message deviation occurred. Furthermore, her toggling of 
modes was a way of her managing the communication patterns of all the speakers present during the appointment.

\section{Conclusion}

Dean and Pollard (2011) have previously argued that although "contextual factors should and do heavily influence ethical and other practice decisions" (p. 159), these do not encompass the totality of what is needed for an interpreter to make effective and ethical decisions. This study has sought to demonstrate the existence, usability and applicability of Dean and Pollard's (2011) value-based decision-making together with the adoption of the four principles of biomedical ethics. Using a single case study in the form of a palliative care appointment, the researcher has delineated by way of the critical incident technique the controls used by the interpreter. These included an addition, not interpreting information and toggling between interpreting modes (consecutive and simultaneous).

The five decision-making junctures analysed in this study through the subjective lens of the researcher depict how the values of the palliative care appointment and the interpreting profession allow a practitioner to identify multiple options for ethical decision-making. This research was inspired by the many concerns previously expressed by medical interpreters who have worked in palliative care settings where they felt at odds in maintaining ethical boundaries while making decisions because of the roles and rules taught to them in their formative years. Future research on interpreter education could analyse recorded interpreting simulations or real assignments to emphasize to students that ethical thinking and the act of interpreting information are interwoven activities.

In this encounter, we were able to see that respect for autonomy was a shared value between the medical interpreter and the members of the palliative care team. When an interpreter has the language of values to describe their work it can be an asset not only to their professional practice but also to their interactions with other healthcare professionals. It is the hope of the researcher that this case study design will inspire others to assess further the way professional interpreters truly practice and improve educational efforts so that practitioners are able to feel that they have the agency to make judgements about their work. 
Contreras-Nourse, M. (2021). Decision-making in paediatric palliative care interpreting. Linguistica

Antverpiensia, New Series: Themes in Translation Studies, 20, 209-226.

\section{References}

Al-Yateem, N. (2012). The effect of interview recording on quality of data obtained: A methodological reflection. Nurse Researcher, 19(4), 31-35. https://doi.org/10.7748/nr2012.07.19.4.31.c9222

Araujo-Lane, Z. (2009). The art of medical interpretation (3rd ed.). Cross Cultural Communications Systems.

Bachiochi, P. D., \& Weiner, S. P. (2002). Qualitative data collection and analysis. In S. G. Rogelberg (Ed.), Handbook of research methods in industrial and organizational psychology (pp. 161-183). Blackwell. https://doi.org/10.1002/9780470756669.ch8

Baker, M., \& Maier, C. (2011). Ethics in interpreter \& translator training. The Interpreter and Translator Trainer, 5(1), 1-14. https://doi.org/10.1080/13556509.2011.10798809

Beauchamp, T. L., \& Childress, J. F. (2013). Principles of biomedical ethics (7th ed.). Oxford University Press.

Bolden, G. B. (2000). Toward understanding practices of medical interpreting: Interpreters' involvement in history taking. Discourse Studies, 2(4), 387-419. https://doi.org/10.1177/ 1461445600002004001

Brisset, C., Leanza, Y., \& Laforest, K. (2013). Working with interpreters in health care: A systematic review and meta-ethnography of qualitative studies. Patient Education and Counseling, 91(2), 131-140. https://doi.org/10.1016/i.pec.2012.11.008

Butterfield, L. D., Borgen, W. A., Amundson, N. E., \& Maglio, A.-S. T. (2005). Fifty years of the critical incident technique: 1954-2004 and beyond. Qualitative Research, 5(4), 475-497. https://doi. org/10.1177/1468794105056924

Committee on bioethics. (2016). Informed consent in decision-making in pediatric practice. Pediatrics, 138(2). https://doi.org/10.1542/peds.2016-1484

Creswell, J. W. (2014). Research design: Qualitative, quantitative, and mixed methods approaches (4th ed.). Sage.

Dean, R. K. (2014). Condemned to repetition?: An analysis of problem-setting and problem-solving in sign language interpreting ethics. Translation \& Interpreting, 6(1), 60-75. https://doi.org/10.12807/ti.106201.2014.a04

Dean, R. K. (2021). Healthcare interpreting ethics: A critical review. In Ş. Susam-Saraeva \& E. Spišiaková (Eds.), The Routledge handbook of translation and health (pp. 198-215). Routledge. https:// doi.org/10.4324/9781003167983-16

Dean, R. K., \& Pollard, R. Q. (2011). Context-based ethical reasoning in interpreting: A demand control schema perspective. Interpreter and Translator Trainer, 5(1), 155-182. https://doi.org/10. $\underline{1080 / 13556509.2011 .10798816}$

Dean, R. K., \& Pollard, R. Q. (2013). The demand control schema: Interpreting as a practice profession. CreateSpace Independent.

Dean, R. K., \& Pollard, R. Q. (2018). Promoting the use of normative ethics in the practice profession of community interpreting. In L. Roberson \& S. Shaw (Eds.), Signed language interpreting in the 21st century: An overview of the profession (pp. 37-64). Gallaudet University Press.

Diefenbach, T. (2008). Are case studies more than sophisticated storytelling?: Methodological problems of qualitative empirical research mainly based on semi-structured interviews. Quality \& Quantity, 43(6), 875-894.https://doi.org/10.1007/s11135-008-9164-0

Dysart-Gale, D. (2005). Communication models, professionalization, and the work of medical interpreters. Health Communication, 17(1), 91-103. https://doi.org/10.1207/s15327027hc17 $\underline{016}$

Gonzalez, S., Lummer, L., Plue, C., \& Ordaz, M. (2018). Community healthcare interpreting. In T. Holcomb \& D. Smith (Eds.), Deaf eyes on interpreting (pp. 209-222). Gallaudet University Press.

Hale, S., \& Napier, J. (2013). Research methods in interpreting: A practical resource. Bloomsbury. 
Contreras-Nourse, M. (2021). Decision-making in paediatric palliative care interpreting. Linguistica Antverpiensia, New Series: Themes in Translation Studies, 20, 209-226.

Juckett, G., \& Unger, K. (2014). Appropriate use of medical interpreters. American Family Physician, 90(7), 476-480.

Kaufert, J. M., \& Lavallee, M. (1999). End-of-life decision making among aboriginal Canadians: Interpretation, mediation, and discord in the communication of "bad news." Journal of Palliative Care, 15(1), 31-38. https://doi.org/10.1177/082585979901500105

Kirby, E., Broom, A., Good, P., Bowden, V., \& Lwin, Z. (2016). Experiences of interpreters in supporting the transition from oncology to palliative care: A qualitative study. Asia-Pacific Journal of Clinical Oncology, 13(5), e497-e505. https://doi.org/10.1111/ajco.12563

Napier, J. (2004). Interpreting omissions: A new perspective. Interpreting, 6(2), 117-142. https://doi. org/10.1075/intp.6.2.02nap

Norris, W. M., Wenrich, M. D., Nielsen, E. L., Treece, P. D., Jackson, J. C., \& Curtis, J. R. (2005). Communication about end-of-life care between language-discordant patients and clinicians: Insights from medical interpreters. Journal of Palliative Medicine, 8(5), 1016-1024. https://doi.org/10.1089/ipm.2005.8.1016

Santoro, J. D., \& Bennett, M. (2018). Ethics of end of life decisions in pediatrics: A narrative review of the roles of caregivers, shared decision-making, and patient centered values. Behavioral Sciences, 8(5), Article 42. https://doi.org/10.3390/bs8050042

Section on hospice and palliative medicine and committee on hospital care. (2013). Pediatric palliative care and hospice care commitments, guidelines, and recommendations. Pediatrics, 132(5), 966-972. https://doi.org/10.1542/peds.2013-2731

Schenker, Y., Fernandez, A., Kerr, K., O'Riordan, D., \& Pantilat, S. Z. (2012). Interpretation for discussions about end-of-life issues: Results from a national survey of health care interpreters. Journal of Palliative Medicine, 15(9), 1019-1026. https://doi.org/10.1089/ipm.2012.0032

Sharma, R., \& Dy, S. (2011). Cross-cultural communication and use of the family meeting in palliative care. American Journal of Hospice and Palliative Medicine, 28(6), 437-444. https://doi.org/10. $1177 / 1049909110394158$

Thomas, G. (2011). A typology for the case study in social science following a review of definition, discourse, and structure. Qualitative Inquiry, 17(6), 511-521. https://doi.org/10.1177/107780 0411409884

Walker, J., \& Shaw, S. (2011). Interpreter preparedness for specialized settings. Journal of Interpretation, 21(1), Article 8.

\footnotetext{
i https://rid.org/ethics/code-of-professional-conduct/

ii https://www.imiaweb.org/code/default.asp

iii Pseudonym.
} 